\title{
Microstructural Evolution and Constitutive Equations of Inconel 718 Alloy under Quasi-static and Quasi-dynamic Conditions
}

\author{
M. Azarbarmas ${ }^{a, b^{*}}$, M. Aghaie-Khafri ${ }^{a 1}$, J.M. Cabrera ${ }^{b}$, J. Calvo ${ }^{b}$ \\ ${ }^{a}$ Faculty of Materials Science and Engineering, K.N. Toosi University of Technology, Postal \\ Code: 1999143344, Tehran, Iran \\ ${ }^{\mathrm{b}}$ Departament de Ciència dels Materials i Enginyeria Metal·lúrgica, ETSEIB - Universitat \\ Politècnica de Catalunya, Av. Diagonal 647, 08028 Barcelona, Spain
}

\begin{abstract}
The deformation behavior of IN718 superalloy was investigated using the hot compression tests in the temperature range of $950-1100{ }^{\circ} \mathrm{C}$, and strain rates covering the quasi-static to the quasidynamic regions $\left(0.001-10 \mathrm{~s}^{-1}\right)$. The shape of flow curves as well as the corresponding work hardening rates analysis was utilized to reveal the dynamic recrystallization (DRX) phenomena. DRX was the dominant restoration mechanism in the whole temperature and strain rate domains, which was characterized by the optical and EBSD images. Extended flow softening was observed at high strain rates due to the adiabatic heating and dislocations interaction. In addition to the assessment the capability of Sellars equations, a new constitutive equation based on the multiple variable regression analysis was proposed for modeling the peak stress as a function of
\end{abstract}

\footnotetext{
${ }^{*}$ Corresponding author.

E-mail addresses: mazarbarmas@ut.ac.ir (M. Azarbarmas)
} 
strain rate and temperature. Besides the simple form of the proposed model, it has a good accuracy for predicting the peak stress.

Keywords: Inconel 718; Hot compression test; Constitutive equation; Dynamic recrystallization; EBSD.

\section{Introduction}

The Nickel-based superalloy IN718 is a precipitation hardenable alloy with high corrosion resistance [1,2], excellent resistance to oxidation [3], high strength [4], adequate ductility and toughness [5], and good machining performance [6]. IN718 is an important material used for modern aero-engines, gas-turbines, extrusion dies, etc. [7-15] Control of the thermomechanical processing is crucial for obtaining favorable microstructure and properties. The hot deformation behavior of IN718 has been widely studied over the past decade using hot compression tests [6,16-19]. Considering Sellars and Tegart equations, some models have been proposed in the form of an hyperbolic-sine [20-22], an exponential [23] and a power law [16,24] for hot compression of IN718. Furthermore, J.M. Zhang et al. [25] have formulated experimental data by considering the shape of the flow stress vs. deformation parameters curves to develop a mathematical model. Recently, M.Z. Hussain et al. [26] have proposed a constitutive relationship for thermo-mechanical processing of IN718 through double multivariate nonlinear regression. Considering hot deformation of IN718, it is worth noting that it is essential to develop comprehensive equations for a wide range of temperature and strain rate.

IN718 is a material with relatively low stacking fault energy [22], in which the presence of solute atoms and phases reduce the mobility of dislocations. Therefore, the main restoration process is dynamic recrystallization (DRX), although the dynamic recovery (DRV) softening plays also a 
competitive role. DRX is an important mechanism that controls the microstructure evolution of the IN718 during the hot working of the material, and indeed, there are numerous works in the literature which have explored the parameters affecting DRX in IN718 [17,27-32]. Due to the enormous influence of DRX on the microstructure and properties after processing, the evaluation of DRX in terms of deformation parameters is vital.

The main goal of the present work is to investigate the hot working behavior of IN718 during the hot compression test at quasi-static and quasi-dynamic conditions. Besides, general constitutive equations and a new model based on the multivariable regression were employed to obtain the hot working constants of the alloy and assess which of them are most appropriate in all conditions.

\section{Experimental procedure}

\subsection{Material}

The starting material in this study was wrought IN718 alloy. Chemical composition of the material is shown in Table 1 . The specimens were solution treated at 1025 for $1 \mathrm{~h}$, followed by cold-water quenching. The initial microstructure comprises equiaxed grains and annealing twins, as is shown in Fig. 1. The average grain size (without twins) was measured to be about $45 \mu \mathrm{m}$ by the linear interce ${ }^{\circ} \mathrm{Cpt}$ method.

\subsection{Compression test}

Cylindrical specimens with a diameter of $5 \mathrm{~mm}$ and a height of $10 \mathrm{~mm}$ were used for hot compression tests. Baehr DIL-805 deformation dilatometer was used for isothermal compression 
tests. Compression tests were conducted up to true strain of about 0.7 under different temperatures $\left(950,1000,1050\right.$ and $\left.1100{ }^{\circ} \mathrm{C}\right)$ and various strain rates $(0.001,0.01,0.1,1$ and 10 $\mathrm{s}^{-1}$ ), for covering the quasi-static and quasi-dynamic condition. A K-type thermocouple was spotwelded at the middle of the specimen to accurately control the heating and cooling rates and measure the specimen temperature. Also, argon gas was utilized as the shielding and quenching gas in the machine. Hot compression tests were conducted in an argon atmosphere. In order to minimize the frictions during the hot deformation and to avoid the adhesion, a Molybdenum foil with a thickness of $0.1 \mathrm{~mm}$ was used between anvils and specimen surface.

\subsection{Microstructural studies}

Hot deformed samples were sectioned parallel to the compression direction. Samples for optical metallographic examination were prepared by mechanically polishing and etching with a solution consisting of $50 \mathrm{ml} \mathrm{HCl}, 50 \mathrm{ml}$ ethanol and $7.5 \mathrm{~g} \mathrm{CuCl}_{2}$. For EBSD analysis, specimens were ground with SiC papers, mechanically polished with diamond slurries and then were polished with $0.04 \mu \mathrm{m}$ colloidal silica solution for one hour. A Zeiss Ultra Plus analytical field emission gun scanning electron microscope (FEG-SEM) equipped with an EBSD detector, provided by HKL Technology, was used for EBSD studies with a step size of $0.25 \mu \mathrm{m}$. analyzing and displaying the EBSD data were done by using the Channel5 software package.

\subsection{Correction of flow curves}

It is necessary to use correction factors for eliminating the effect of interfacial friction. A simplified analysis of the barrel compression test based on the upper-bound theory [33] was used to remove the friction effects on the flow curves. 
Generally, the occurrence of DRX can be identified from the appearance of a peak stress in the flow curves. Nevertheless, in some cases detection of this peak is difficult under hot working conditions. The initiation of DRX can also be identified from inflection point of the strain hardening rate against stress curves [34,35]. The first derivative of the true stress versus true strain yields the work hardening rate $(\theta)$. The $\theta$ values were obtained by averaging the slopes of two adjacent points for each data point using Origin program as follows:

$$
\frac{1}{2}\left(\frac{y_{i+1}-y_{i}}{x_{i+1}-x_{i}}+\frac{y_{i}-y_{i-1}}{x_{i}-x_{i-1}}\right)
$$

where $\mathrm{x}$ and $\mathrm{y}$ are the coordinates of each data point. For solving noise problems, a curve smoothing by fitting a seven to nine-order polynomial to the stress-strain curves was used to eliminate the fluctuations during differentiation[36,37]. In this study, following the removal of the elastic portions of curves, each curve was friction-corrected and then was smoothed with a high-order polynomial.

\section{Results and discussion}

\subsection{Corrected flow curves}

The friction-corrected flow curves obtained for different temperatures and strain rates are presented in Fig. 2. Most of samples exhibit typical DRX flow curves with a clear single peak stress followed by a gradual decrease towards a steady state stress. Having a single peak behavior is the main characteristic of discontinuous dynamic recrystallization[35], and shows that recrystallization initiates in new cycles before completion of the current cycles [36]. Thus, different grains are at different state of recrystallization development during deformation and the single peak flow curve is the averaged flow stress of grains at various stages of recrystallization. 
As can be observed in Fig. 2, the peaks of flow curves become less obvious with decreasing strain rate and increasing temperature. The abnormal stress drop beyond the peak stress in the case of samples deformed at $10 \mathrm{~s}^{-1}$ strain rate is due to the adiabatic deformation heating. When hot compression is performed at strain rates of $10 \mathrm{~s}^{-1}$ and higher, the degree of temperature rise due to adiabatic heating is high and the heat cannot dissipate to the surrounding environment during the short time periods of the tests [38]. Additionally, considering that the deformation process is very fast, it is almost impossible for the testing machine to compensate the temperature deviation during the compression test. On DIL-805 deformation dilatometer, the instantaneous temperature in the stable center region of specimen was measured by a welded thermocouple during hot deformation. Fig.3a shows the adiabatic deformation heating for the specimen deformed at high strain rate of $10 \mathrm{~s}^{-1}$ and $1050{ }^{\circ} \mathrm{C}$. Similar behavior at $10 \mathrm{~s}^{-1}$ strain rate has been reported by $\mathrm{H}$. Mirzadeh et al. for hot compression of steels [36,39]. It can be observed that the increase in temperature following the peak point is significantly high owing to the adiabatic heating. The temperature rise results in reduction in the flow stress of the sample, i.e., the peak stress (or the stress softening) in this condition is related to the temperature increment rather than to the onset of DRX. Analogous plots at $\mathrm{T}=1050{ }^{\circ} \mathrm{C}$ and $10 \mathrm{~s}^{-1}$ strain rate are presented in Fig.3b. This figure shows that the adiabatic heating during deformation is negligible for samples compressed at strain rates lower than $10 \mathrm{~s}^{-1}$.

It is clear from Fig. 2 that the plastic region of the flow curve consists of three stages: i) work hardening, ii) softening and iii) steady state. The first stage is the work hardening region, in which dislocation density continuously increases and the flow stress quickly increases with the increase of the strain. In the softening region, the dislocation density reaches a critical level, and DRX occurs. During the nucleation and growth of recrystallized grains the number of 
dislocations is reduced and thereby the flow stress decreases. Finally, at the steady state, there is a balance between work hardening and dynamic softening.

\subsection{Microstructural characteristics}

Hot deformation at different temperatures and strain rates results in grain elongation, boundaries serration, substructure formation and finally the onset of DRX after a critical strain. As an illustrative example, the effects of deformation temperature on the microstructure of the specimens under the strain rate of $0.01 \mathrm{~s}^{-1}$ is shown in Fig. 4. It can be observed that for a given nominal strain of 0.7 , the fraction of recrystallized grains increases with the increase of the deformation temperature. Considering that the occurrence of DRX, at a given initial grain size, is dependent on the distribution and of dislocation density [21], and knowing that the increasing of the deformation temperature decreases the critical dislocation density, the critical strain for the onset of DRX decreases. As depicted in Fig. 4, with increasing the temperature the microstructures transform from a duplex or "necklace" to a completely recrystallized structure and the recrystallized grain size increases. The recrystallized grain growth is due to high mobility of the grain boundaries at high temperatures.

Fig. 5 depicts the influences of strain rate on the microstructures of deformed specimens at the deformation temperature of $1050{ }^{\circ} \mathrm{C}$. It is clear that the recrystallized grain size decreases with increasing strain rate. Moreover, the fraction of DRX decreases with increasing the strain rate. The exceptional case for the relationship of grain size and the fraction of DRX with strain rate is the specimen compressed at strain rate of $10 \mathrm{~s}^{-1}$, which shows higher grain size and greater fraction of DRX in comparison with the specimen deformed at strain rate of $1 \mathrm{~s}^{-1}$. The promotion of DRX at high strain rate of $10 \mathrm{~s}^{-1}$ can be ascribed to the adiabatic heating and increased rate of 
dislocation accumulation. Adiabatic heating within the specimen facilitates DRX nucleation and grain boundary migration and thereby stimulates DRX process. On the other hand, due to the strong dislocation-dislocation interaction and weak recovery during plastic deformation at high strain rate, the dislocation density increases. Distributions of sub-boundaries inside the elongated grains have been compared for samples deformed at temperature of $1100{ }^{\circ} \mathrm{C}$ and strain rates of 10 and $1 \mathrm{~s}^{-1}$ in Fig. 6. The more density of low-angle grain boundaries for sample compressed at strain rate of $10 \mathrm{~s}^{-1}$ approves the increasing dislocation density with increasing the strain rate. The increased dislocation density decreases the recrystallization temperature noticeably [40]. Therefore, the high volume fraction and grain size of recrystallized grains at strain rate of $10 \mathrm{~s}^{-1}$ are resonable.

In a single-peak DRX process, nucleation occurs essentially along existing grain boundaries (necklace mechanism). The growth of new grains is limited by the concurrent deformation as a result of decreased driving force for their subsequent growth due to rising the dislocation density [41]. The DRX process continues until the completion of the first layer of necklace to cover the entire grain boundary. Afterward, the subsequent layers form at the recrystallization front between the recrystallized and un-recrystallized portions.

The OIM band contrast microstructures of annealed sample and compressed at $1000^{\circ} \mathrm{C}-0.1 \mathrm{~s}^{-1}$ are presented in Fig. 7. It is evident from Fig. 7a that the initial annealed microstructure (preceded to hot deformation) consisted of equiaxed grains with a large quantity of annealing twin boundaries and negligible fraction of low angle boundaries. The equiaxed grains are the result of static recrystallization and grain growth during the annealing heat treatment. There are two types of twin boundaries in the structure, i) the straight and ii) the curved twin boundaries which are indicated with white and yellow arrows, respectively, shown in Fig. 7a. It is believed that the 
straight twin boundaries are coherent and the curved are incoherent [42]. As expected for a material with low stacking fault energy [43] the presence of this high fraction of twin boundaries in the microstructure shows that formation of annealing twins is an important phenomenon during the recrystallization of this alloy. Twin domains are favorable nucleation sites for DRX due to their high stored deformation energy [44].

Fig. $7 \mathrm{~b}$ depicts plenty of sub-boundaries in the deformed and un-recrystallized matrix of the sample deformed at $1000^{\circ} \mathrm{C}-0.1 \mathrm{~s}^{-1}$, which is a result of dislocation generation and dislocation boundary formation during the plastic deformation and dynamic recovery. However, the new DRX grains consume the deformed microstructure and thereby decrease the fraction of low angle boundaries. Besides, most of the twin boundaries in the matrix have been diminished. Some of the pre-existing twins have lost their twin characteristics and curved due to the effects of concurrent deformation $[43,45]$, showed by yellow arrow in Fig. 7 b. It is noteworthy that a large fraction of newly generated boundaries after the initiation of DRX have twin relationship. It is obvious from Fig $7 \mathrm{~b}$ that the dislocation sub-boundaries behind the bulged parts are free of twins. Therefore, it can be pointed out twins inside DRX grains form during the growth of DRX grains. This is in line with the other reported observations [46].

The typical macrograph and micrograph of specimens deformed under $1050{ }^{\circ} \mathrm{C}-10 \mathrm{~s}^{-1}$ are shown in Fig. 8a and b, respectively. These images show large amount of local deformation bands forming about $45^{\circ}$ angles to the compression direction and indicate the existence of the instability in the form of unstable flow due to the flow localization at high strain rates. The same phenomenon has also been found in compression tests of superaustenitic stainless steel and has been interpreted as a result of flow localization [47]. 


\subsection{Constitutive equations based on Sellars models}

Several empirical equations have been presented to characterize the hot deformation behavior and to obtain constitutive equations of alloys. These equations are commonly employed to define the flow stress as a function of strain rate and deformation temperature[48,49]. Generally, a constitutive equation is determined by formulating experimental data [25].

Hot deformation can be conceived as a thermally-activated process which is modeled with strain rate equations like to those used in creep modeling [50]. The combined effect of temperature and strain rate is classically unified through the Zener-Hollomon parameter (Z), whose physical interpretation is the strain rate factor compensated by temperature.

$$
\mathrm{Z}=\operatorname{sexp}\left(\frac{\mathrm{Q}}{\mathrm{RT}}\right)
$$

where $\&$ is strain rate $\left(\mathrm{s}^{-1}\right), \mathrm{Q}$ is hot deformation activation energy $(\mathrm{kJ} / \mathrm{mol}), \mathrm{R}$ is the gas constant $\left(8.314 \mathrm{~kJ} / \mathrm{mol} \mathrm{K}^{-1}\right)$, and $\mathrm{T}$ is deformation temperature $(\mathrm{K})$.

Concerning developing constitutive equations, the $\mathrm{Z}$ parameter can be associated with the flow stress in different ways. Three types of equations are mostly used according to the deformation conditions, involving exponential, power and hyperbolic sine functions [51-53].

$$
Z=\operatorname{dexp}\left(\frac{Q}{R T}\right)=f(\sigma)=\left\{\begin{array}{c}
A_{1} \exp (\beta \sigma) \\
A_{2} \sigma^{n^{\prime}} \\
A_{3}[\operatorname{snh}(\alpha \sigma)]^{n}
\end{array}\right.
$$

where, $A_{1}, A_{2}, A_{3}, n^{\prime}, n, \beta$ and $\alpha\left(\approx \beta / n^{\prime}\right)$ are experimentally determined temperatureindependent material constants. In these equations, the flow stress is related to the strain rate and temperature of deformation. Nevertheless, such flow stress definition must be considered as rate equations rather than constitutive equations because there is no dependence on strain in the 
equations. Typically the latter equations can be applied to characteristic stresses such as steady state or peak stress. The method used for obtaining the characteristic stresses, peak and steady state stress, is illustrated in Fig. 9. It appears from Fig. 10 that the peak stress and the steady-state stress have linear relationship especially for samples compressed at low strain rates. Although in the in literature, there are reports of using both the peak stress [54] and the steady-state stress [16] for formulating the constitutive equations, one should notice that it is not often possible to determine the steady state stress accurately and the adiabatic heating can drop the flow stress at high strain rates. Therefore, it seems that it is better to use the peak stress in constitutive equations rather than steady state stresses.

Eq. (2) can be rearranged to yield the following equations:

$$
\ln \&+\left(\frac{Q}{R}\right) \frac{1}{T}=\left\{\begin{array}{l}
\ln A_{1}+\beta \sigma \\
\ln A_{2}+n^{\prime} \ln \sigma \\
\ln A_{3}+n \ln [\sinh (\alpha \sigma)]
\end{array}\right.
$$

$\beta, n^{\prime}$ and $n$ can also be derived by partial differentiation of Eq. (3) at a given deformation temperature:

$$
\left\{\begin{aligned}
\beta & =\left[\frac{\partial \ln \&}{\partial \sigma}\right]_{\mathrm{T}} \\
\mathrm{n}^{\prime} & =\left[\frac{\partial \ln \&}{\partial \ln \sigma}\right]_{\mathrm{T}} \\
\mathrm{n} & =\left[\frac{\partial \ln \&}{\partial \ln [\sinh (\alpha \sigma)]}\right]_{\mathrm{T}}
\end{aligned}\right.
$$

The slopes of the curves of $\ln \&$ versus $\sigma_{\mathrm{p}}, \ln \sigma_{\mathrm{P}}$ and $\ln [\sinh (\alpha \sigma)]$ can be employed for determining the values of $\beta, \mathrm{n}^{\prime}$ and $\mathrm{n}$, respectively. The stress multiplier $\alpha$ can be estimated by knowing the values of $\beta$ and $n^{\prime}\left(\alpha \approx \beta / n^{\prime}\right.$ ) [55], which is obtained to be 0.006 . Aforementioned 
plots are presented in Fig. 11. The average values of $\beta, n^{\prime}$ and $n$ were calculated by linear regression of the corresponding curves and are listed in Table 2. The adjusted $\mathrm{R}^{2}$ error values presented in Table 2 reveal that the linear regression results are acceptable.

Partial differentiation of Eq. (4) at constant strain can be used for calculating the value of deformation activation energy (Q). The necessary expressions are as follows:

$$
Q=\left\{\begin{array}{l}
\mathrm{R} \beta\left[\frac{\partial \sigma}{\partial(1 / \mathrm{T})}\right]_{\&} \\
\operatorname{Rn}^{\prime}\left[\frac{\partial \ln \sigma}{\partial(1 / T)}\right]_{\&} \\
\operatorname{Rn}\left[\frac{\partial \ln [\sinh (\alpha \sigma)]}{\partial(1 / T)}\right]_{\&}
\end{array}\right.
$$

Based on Eq.(6) the slope of the plots of $\sigma_{\mathrm{P}}, \ln \sigma_{\mathrm{P}}$ and $\ln \sinh \left(\alpha \sigma_{\mathrm{P}}\right)$ versus the reciprocal of the absolute temperature can be utilized for calculating the value of $\mathrm{Q}$. The required plots are shown in Fig. 12. As is shown in Table 3, the average values of 442, 409, and $437 \mathrm{~kJ} / \mathrm{mol}$ were obtained for activation energy based on the exponential, power and hyperbolic sine laws, respectively. It can be observed that all the values are close to each other. The average activation energy of hot deformation was considered to be $429 \mathrm{~kJ} / \mathrm{mol}$ which is comparable to the values reported for hot deformation of IN718: $443 \mathrm{~kJ} / \mathrm{mol}$ by Y. Wang et al. [21] and $429 \mathrm{~kJ} / \mathrm{mol}$ by L. Cheng et al. [56]. However, the activation energy is significantly higher than the activation energy for selfdiffusion of nickel (278 kJ/mol [57]). The higher Q value can be ascribed to the influences of alloying elements which pin the motion of the dislocations and grain boundaries. The final obtained equations after substituting $Q, n, \dot{n}, \alpha$ and $\beta$ values are as follow: 


$$
\ln \&+\frac{51600}{T}=\left\{\begin{array}{l}
\ln A_{1}+0.026 \sigma \\
\ln A_{2}+5.029 \ln \sigma \\
\ln A_{3}+3.462 \ln [\sinh (0.005 \sigma)]
\end{array}\right.
$$

\subsection{Peak Stress as a Function of the Zener-Hollomon Parameter}

Considering Eq. (3), the curves of $\ln \mathrm{Z}$ against $\sigma_{\mathrm{P}}, \ln \sigma_{\mathrm{P}}$, or $\ln \sinh \left(\alpha \sigma_{\mathrm{P}}\right)$ were plotted, Fig. 13, and used to model the relationship between $\mathrm{Z}$ and $\sigma_{\mathrm{P}}$. Using a linear regression, the following equations with new constants were derived:

$$
Z=\exp \left(\frac{429152}{\mathrm{RT}}\right)=\left\{\begin{array}{l}
\left(3.16 \times 10^{13}\right) \mathrm{e}^{\left(0.027 \sigma_{\mathrm{P}}\right)} \\
61023 \sigma_{\mathrm{P}}^{4.957} \\
\left(2.57 \times 10^{15}\right)\left[\operatorname{Sinh}\left(0.0054 \sigma_{\mathrm{P}}\right)\right]^{3.562}
\end{array}\right.
$$

Considering Table 4, the power law equation has the highest adjusted $\mathrm{R}^{2}$ value. Besides, this equation is simple and easy to use. Therefore, it is preferred to use the power law for modeling the hot deformation behavior of IN718 in the temperature range of 950-1100 ${ }^{\circ} \mathrm{C}$ and strain rate range of $0.001-10 \mathrm{~s}^{-1}$. However, the hyperbolic sine law has also a good fit and the exponential equation is not precise in the present investigation. Finally, in the order to increase the accuracy of peak stress calculation in IN718 alloy under the deformation condition used in this study the simplified following equations can be used:

$$
\left\{\begin{array}{c}
\sigma_{\mathrm{P}}=37.04 \operatorname{Ln} Z-1151 \\
\sigma_{\mathrm{P}}=185 \times \operatorname{Sinh}^{-1}\left(12475 \times \mathrm{Z}^{0.28}\right) \\
\sigma_{\mathrm{P}}=0.108 \times \mathrm{Z}^{0.202}
\end{array}\right.
$$




\subsection{A new model based on multivariable regression}

Based on the experimental data of hot compression tests, a non-linear constitutive model is constructed by multiple linear regression analysis. Fig. 11a shows that a linear relationship exists between $\operatorname{Ln} \sigma_{P}$ and $L n \& \&$ at constant temperature. On the other hand, it is clear from Fig. $12 b$ that at a given strain rate there is a linear relation between $\operatorname{Ln} \sigma_{P}$ and $(1 / T)$. By simple linear regression analysis of Fig $11 a$ and $12 b$, the following regression equations can be derived:

$\operatorname{Ln} \sigma_{P}=A \operatorname{Ln} \& \sigma_{P}(T)$

$\operatorname{Ln} \sigma_{P}=B\left(\frac{1}{T}\right)+\sigma_{P}(\&)$

It is important to note that the slope of ${ }^{L n} \sigma_{P}$ - Ln\& curve is independent of temperature and that of ${ }^{L n \sigma_{P}}-\frac{1}{T}$ curve is independent of strain rate in Fig 11 and $12 b$, respectively. It means that $A$ and B in Eq. (10) and (11) are constant at all temperatures and strain rates. Thus, the following expression can be proposed for the peak stress:

$\operatorname{Ln} \sigma_{P}=A \operatorname{Ln} \&+B\left(\frac{1}{T}\right)+C$

This equation is in the form of $y=y_{0}+a x_{1}+b x_{2}$. Therefore, the multivariate linear regression can be used for finding the A, B and C constants. Based on the constructing data, the peak stress model or the constitutive equation for the hot deformation of IN718 is obtained as follows:

$\operatorname{Ln} \sigma_{P}=0.199 \operatorname{Ln} \& \frac{10709.6}{T}-2.458$

Fig. 14a shows 3D illustration of the experimental and calculated peak stress based on the Eq.

(13). For better assessing the prediction capabilities of the model, results of hot compression 
tests of IN 718 reported by H. Y. Zhang et al.[22] and J. M. Zhang et al. [25]were utilized. The important criterion in selection of data from the literature was that the strain rate or deformation temperature of those works should differ from that of our work. The experimental peak stress of IN 718 obtained at deformation temperatures of $980[25]$ and $1060{ }^{\circ} \mathrm{C}[22]$ under various strain rates are presented in Fig. $14 \mathrm{~b}$. This figure shows that the prediction of the model is very close to that of the test case, especially for higher temperatures. The adjusted $R^{2}$ of 0.962 and 0.975 for deformation temperatures of 980 and $1060{ }^{\circ} \mathrm{C}$, respectively, shows that the established constitutive relationship is capable of describing the peak stress of the alloy at different strain rates and deformation temperatures. By some algebraic manipulations of Eq. (12), the following equation is derived.

$$
C^{\prime} \sigma_{P}^{\frac{1}{A}}=\& \exp \left(\frac{B}{A . T}\right)
$$

By comparing Eq. (14) with the second expression of Eq. (3), A and B constants can be physically described. It can be observed that $1 / A$ and $B R / A$ represent $\mathrm{n}^{\prime}$ and activation energy (Q), respectively.

The advantage of the new proposed constitutive equation in comparison to the Sellars-Tegart based equations is that the propos equation is simple and can be easily obtained. Moreover, there is no need for calculating the activation energy of the hot deformation. 


\section{Conclusions}

A step-by-step data analysis of the hot compression behavior of IN718 alloy at temperatures ranging from 950 to $1100{ }^{\circ} \mathrm{C}$ and strain rates of 0.001 to $10 \mathrm{~s}^{-1}$ resulted in the following principal conclusions:

-The inflection analysis in the work hardening rate versus stress plots as well as optical and EBSD images confirmed that the flow curves exhibited typical DRX behavior.

-The specimen compressed at high strain rate showed an exceptional DRX behavior and extended softening because of the adiabatic heating and strong interaction between the dislocations.

- The microstructure of the alloy at high temperatures and high strain rates had a large amount of local deformation bands forming about $45^{\circ}$ angles to the compression direction showing an instable behavior.

-Among Sellars constitutive equations, the power law constitutive equation has the highest correlation coefficient and also is simple and easy to use.

-A new multivariable regression based model was proposed for obtaining constitutive equation of the material. The simple proposed model showed a good accuracy for predicting the peak stress as a function of strain rate and temperature.

\section{Acknowledgements}

The authors would like to thank Fundacio' CTM Centre Tecnologic (Manresa, Spain) and Polytechnic University of Catalonia for providing the facilities for the experimental work. The authors also thank Dr. A. Gironés Molera, A. hernandez and J. Alberto Muñoz Bolaños for their assistance in the experiments. 


\section{References}

[1] Sui F-L, Xu L-X, Chen L-Q, Liu X-H. Processing map for hot working of Inconel 718 alloy. Journal of Materials Processing Technology 2011;211:433-40.

[2] Rezende MC, Araújo LS, Gabriel SB, Dille J, De Almeida LH. Oxidation assisted intergranular cracking under loading at dynamic strain aging temperatures in Inconel 718 Superalloy. Journal of Alloys and Compounds 2015.

[3] Khaja S, Mehta KK, Babu RV, Devi RSR, Singh AK. Mechanical Properties Anisotropy of Isothermally Forged and Precipitation Hardened Inconel 718 Disk. Metallurgical and Materials Transactions A 2015;46:1140-53.

[4] Kulawik K, Buffat PA, Kruk A, Wusatowska-Sarnek AM, Czyrska-Filemonowicz A. Imaging and characterization of $\gamma^{\prime}$ and $\gamma^{\prime \prime}$ nanoparticles in Inconel 718 by EDX elemental mapping and FIB-SEM tomography. Materials Characterization 2015;100:74-80.

[5] Araujo LS, Dos Santos DS, Godet S, Dille J, Pinto AL, De Almeida LH. Analysis of Grain Boundary Character in a Fine-Grained Nickel-Based Superalloy 718. Journal of Materials Engineering and Performance 2014;23:4130-5.

[6] Zheng W, Song Z, Lei T, Yong Q, Xie Q. Static recrystallization behavior of Inconel 718 alloy during thermal deformation. Journal of Wuhan University of Technology-Mater Sci Ed 2014;29:379-83.

[7] Kumar S, Rao GS, Chattopadhyay K, Mahobia GS, Srinivas NCS, Singh V. Effect of surface nanostructure on tensile behavior of superalloy IN718. Materials \& Design $2014 ; 62: 76-82$.

[8] Kundin J, Mushongera L, Emmerich H. Phase-field modeling of microstructure formation during rapid solidification in Inconel 718 superalloy. Acta Materialia 2015;95:343-56.

[9] Prasad K, Sarkar R, Ghosal P, Kumar V. Tensile deformation behaviour of forged disc of IN 718 superalloy at $650^{\circ}$ C. Materials \& Design 2010;31:4502-7.

[10] Gill AS, Telang A, Vasudevan VK. Characteristics of Surface Layers Formed on Inconel 718 by Laser Shock Peening With and Without a Protective Coating. Journal of Materials Processing Technology 2015.

[11] Thirugnanasambantham KG, Natarajan S. Degradation Through Erosion: Mechanistic Studies on IN-718 Superalloy Under Hot Air Jet Conditions. Journal of Materials Engineering and Performance n.d.:1-9. 
[12] Candioto KCG, Caliari FR, Reis DAP, Couto AA, Nunes CA. Characterization of the Superalloy Inconel 718 After Double Aging Heat Treatment. Mechanical and Materials Engineering of Modern Structure and Component Design, Springer; 2015, p. 293-300.

[13] Wang Y, Shao WZ, Zhen L, Yang C, Zhang XM. Tensile deformation behavior of superalloy 718 at elevated temperatures. Journal of Alloys and Compounds 2009;471:331-5. doi:10.1016/j.jallcom.2008.03.082.

[14] Chamanfar A, Sarrat L, Jahazi M, Asadi M, Weck A, Koul AK. Microstructural Characteristics of Forged and Heat Treated Inconel-718 Disks. Materials \& Design 2013;52:791-800.

[15] Brooks JW. Forging of superalloys. Materials \& Design 2000;21:297-303.

[16] Medeiros SC, Prasad Y, Frazier WG, Srinivasan R. Microstructural modeling of metadynamic recrystallization in hot working of IN 718 superalloy. Materials Science and Engineering: A 2000;293:198-207.

[17] Wang Y, Shao WZ, Zhen L, Zhang XM. Microstructure evolution during dynamic recrystallization of hot deformed superalloy 718. Materials Science and Engineering: A 2008;486:321-32.

[18] Park NK, Kim IS, Na YS, Yeom JT. Hot forging of a nickel-base superalloy. Journal of Materials Processing Technology 2001;111:98-102.

[19] Zhou LX, Baker TN. Effects of strain rate and temperature on deformation behaviour of IN 718 during high temperature deformation. Materials Science and Engineering: A 1994;177:1-9.

[20] Qiu JW, Liu Y, Liu B, Liu YB, Wang B, Ryba E, et al. Optimizing the hot-forging process parameters for connecting rods made of PM titanium alloy. Journal of Materials Science 2012;47:3837-48. doi:10.1007/s10853-011-6239-4.

[21] Wang Y, Shao WZ, Zhen L, Yang L, Zhang XM. Flow behavior and microstructures of superalloy 718 during high temperature deformation. Materials Science and Engineering: A 2008;497:479-86.

[22] Zhang HY, Zhang SH, Li ZX, Cheng M. Hot die forging process optimization of superalloy IN718 turbine disc using processing map and finite element method. Proceedings of the Institution of Mechanical Engineers, Part B: Journal of Engineering Manufacture 2010;224:103-10.

[23] Lin YC, Li K-K, Li H-B, Chen J, Chen X-M, Wen D-X. New constitutive model for hightemperature deformation behavior of inconel 718 superalloy. Materials \& Design 2015;74:108-18. 
[24] Medeiros SC, Prasad Y, Frazier WG, Srinivasan R. Modeling grain size during hot deformation of IN 718. Scripta Materialia 1999;42.

[25] Zhang JM, Gao ZY, Zhuang JY, Zhong ZY. Mathematical modeling of the hotdeformation behavior of superalloy IN718. Metallurgical and Materials Transactions A 1999;30:2701-12.

[26] Hussain MZ, Li F, Wang J, Yuan Z, Li P, Wu T. Determination of Constitutive Equation for Thermo-mechanical Processing of INCONEL 718 Through Double Multivariate Nonlinear Regression Analysis. Journal of Materials Engineering and Performance n.d.:113.

[27] Wang Y, Zhen L, Shao WZ, Yang L, Zhang XM. Hot working characteristics and dynamic recrystallization of delta-processed superalloy 718. Journal of Alloys and Compounds 2009;474:341-6.

[28] Feng D, Zhang XM, Liu SD, Deng YL. Constitutive equation and hot deformation behavior of homogenized $\mathrm{Al}-7.68 \mathrm{Zn}-2.12 \mathrm{Mg}-1.98 \mathrm{Cu}-0.12 \mathrm{Zr}$ alloy during compression at elevated temperature. Materials Science and Engineering: A 2014;608:63-72. doi:http://dx.doi.org/10.1016/j.msea.2014.04.055.

[29] Guimaraes AA, Jonas JJ. Recrystallization and aging effects associated with the high temperature deformation of Waspaloy and Inconel 718. Metallurgical Transactions A 1981;12:1655-66.

[30] Na Y-S, Yeom J-T, Park N-K, Lee J-Y. Prediction of microstructure evolution during high temperature blade forging of a Ni- Fe based superalloy, Alloy 718. Metals and Materials International 2003;9:15-9.

[31] Zhou LX, Baker TN. Effects of dynamic and metadynamic recrystallization on microstructures of wrought IN-718 due to hot deformation. Materials Science and Engineering: A 1995;196:89-95.

[32] Srinivasan N, Prasad YVRK. Microstructural control in hot working of IN-718 superalloy using processing map. Metallurgical and Materials Transactions A 1994;25:2275-84.

[33] Ebrahimi R, Najafizadeh A. A new method for evaluation of friction in bulk metal forming. Journal of Materials Processing Technology 2004;152:136-43.

[34] Solhjoo S. Determination of flow stress and the critical strain for the onset of dynamic recrystallization using a hyperbolic tangent function. Materials \& Design 2014;54:390-3.

[35] Hajkazemi J, Zarei-Hanzaki A, Sabet M, Khoddam S. Double-hit compression behavior of TWIP steels. Materials Science and Engineering: A 2011;530:233-8. 
[36] Mirzadeh H, Najafizadeh A, Moazeny M. Flow curve analysis of 17-4 PH stainless steel under hot compression test. Metallurgical and Materials Transactions A 2009;40:2950-8.

[37] Mirzadeh H, Cabrera JM, Najafizadeh A. Constitutive relationships for hot deformation of austenite. Acta Materialia 2011;59:6441-8.

[38] Cao Y, Di H, Zhang J, Yang Y. Dynamic behavior and microstructural evolution during moderate to high strain rate hot deformation of a $\mathrm{Fe}-\mathrm{Ni}-\mathrm{Cr}$ alloy (alloy $800 \mathrm{H}$ ). Journal of Nuclear Materials 2015;456:133-41. doi:10.1016/j.jnucmat.2014.09.030.

[39] Mirzadeh H, Najafizadeh A. Hot deformation and dynamic recrystallization of 17-4 PH stainless steel. ISIJ International 2013;53:680-9.

[40] Cao Y, Di H, Zhang J, Zhang J, Ma T, Misra RDK. An electron backscattered diffraction study on the dynamic recrystallization behavior of a nickel - chromium alloy $(800 \mathrm{H})$ during hot deformation. Materials Science \& Engineering A 2013;585:71-85. doi:10.1016/j.msea.2013.07.037.

[41] Mirzadeh H, Cabrera JM, Najafizadeh A. Modeling and prediction of hot deformation flow curves. Metallurgical and Materials Transactions A 2012;43:108-23.

[42] Mirzadeh H, Cabrera JM, Najafizadeh A, Calvillo PR. EBSD study of a hot deformed austenitic stainless steel. Materials Science and Engineering: A 2012;538:236-45.

[43] Dehghan-Manshadi A, Barnett MR, Hodgson PD. Hot deformation and recrystallization of austenitic stainless steel: Part I. Dynamic recrystallization. Metallurgical and Materials Transactions A 2008;39:1359-70.

[44] Park SH, Lee JH, Yu H, Yoon J, You BS. Effect of cold pre-forging on the microstructure and mechanical properties of extruded $\mathrm{Mg}-8 \mathrm{Sn}-1 \mathrm{Al}-1 \mathrm{Zn}$ alloy. Materials Science and Engineering: A 2014;612:197-201.

[45] Vander Voort GF, Friel JJ. Image analysis measurements of duplex grain structures. Materials Characterization 1992;29:293-312.

[46] Beladi H, Cizek P, Hodgson PD. Dynamic recrystallization of austenite in Ni-30 Pct Fe model alloy: microstructure and texture evolution. Metallurgical and Materials Transactions A 2009;40:1175-89.

[47] Pu E, Zheng W, Xiang J, Song Z, Li J. Hot deformation characteristic and processing map of superaustenitic stainless steel S32654. Materials Science and Engineering: A 2014;598:174-82.

[48] Li J, Liu J, Cui Z. Characterization of hot deformation behavior of extruded ZK60 magnesium alloy using 3D processing maps. Materials \& Design 2014;56:889-97. 
[49] Dehghan H, Abbasi SM, Momeni A, Karimi Taheri A. On the constitutive modeling and microstructural evolution of hot compressed A286 iron-base superalloy. Journal of Alloys and Compounds 2013;564:13-9.

[50] Roostaei M, Parsa MH, Mahmudi R, Mirzadeh H. Hot compression behavior of GZ31 magnesium alloy. Journal of Alloys and Compounds 2015;631:1-6.

[51] Frost HJ, Ashby MF. Deformation mechanism maps: the plasticity and creep of metals and ceramics 1982.

[52] Sellars CM, Tegart WJ. La Relation Entre La Résistance et la Structure Dans la Déformation a Chaud. Mém Sci Met n.d.;23:731.

[53] Jonas JJ, Sellars CM, Tegart WJM. Strength and structure under hot-working conditions. Metallurgical Reviews 1969;14:1-24.

[54] Satheesh Kumar SS, Raghu T, Bhattacharjee PP, Appa Rao G, Borah U. Constitutive modeling for predicting peak stress characteristics during hot deformation of hot isostatically processed nickel-base superalloy. Journal of Materials Science 2015;50:6444-56. doi:10.1007/s10853-015-9200-0.

[55] Quan G, Mao Y, Li G, Lv W, Wang Y, Zhou J. A characterization for the dynamic recrystallization kinetics of as-extruded 7075 aluminum alloy based on true stress-strain curves. Computational Materials Science 2012;55:65-72.

[56] Cheng L, Xue X, Tang B, Liu D, Li J, Kou H, et al. Deformation behavior of hot-rolled IN718 superalloy under plane strain compression at elevated temperature. Materials Science and Engineering: A 2014;606:24-30.

[57] Ning Y, Yao Z, Guo H, Fu MW. Hot deformation behavior and hot working characteristic of Nickel-base electron beam weldments. Journal of Alloys and Compounds 2014;584:494-502. doi:10.1016/j.jallcom.2013.09.112.

\section{Figures Captions}

Fig. 1. Optical micrograph of the studied IN718 before hot deformation.

Fig. 2. True stress-true strain curves obtained in hot compression of IN718 at different strain rates and temperatures of (a) 950 , (b) 1000 , (c) 1050 and (d) $1100{ }^{\circ} \mathrm{C}$.

Fig. 3. (a) True stress and temperature versus true strain curves for samples deformed at $1050{ }^{\circ} \mathrm{C}$ and strain rate of (a) 10 and (b) $1 \mathrm{~s}^{-1}$. 
Fig. 4. Microstructure of IN718 alloy deformed at strain rate of $0.01 \mathrm{~s}^{-1}$ and temperature of (a) 950, (b) 1000, (c) 1050 and (d) $1100{ }^{\circ} \mathrm{C}$; showing DRX microstructures.

Fig. 5. Microstructure of IN718 alloy deformed at strain rate of (a) 0.001 , (b) 0.01 , (c) 0.1 , (d) 1 and (e) $10 \mathrm{~s}^{-1}$, and $1050{ }^{\circ} \mathrm{C}$; showing DRX microstructures.

Fig. 6. The OIM band contrast microstructures for samples deformed at $1100^{\circ} \mathrm{C}$ and strain rate of (a) $0.1 \mathrm{~s}^{-1}$ and (b) $10 \mathrm{~s}^{-1}$. The high and low angle boundaries are shown as black and white lines, respectively.

Fig. 7. The OIM band contrast microstructures for (a) annealed sample and (b) sample deformed at $1000^{\circ} \mathrm{C}-0.1 \mathrm{~s}^{-1}$; the high and low angle boundaries are shown as black and white lines, respectively; $\Sigma 3$ twin boundaries are shown as red lines.

Fig. 8. (a) Macrograph and (b) micrograph of IN 718 alloy deformed at $1050{ }^{\circ} \mathrm{C}-10 \mathrm{~s}^{-1}$.

Fig. 9. (a) Some of work hardening rate-true stress curves in various conditions; (b) Method used for determination of peak and steady state stresses.

Fig. 10. The linear relationship between (a) the peak stress and steady state stress at various strain rates, and (b) variations of $\ln \sigma$ and $\ln \&$.

Fig. 11. Plots used for calculation of (a) $n^{\prime}$, (b) $\beta$ and (c) $n$ values.

Fig. 12. Plots of (a) $\sigma_{\mathrm{P}}$, (b) $\ln \sigma_{\mathrm{P}}$, and (c) $\ln \sinh \left(\alpha \sigma_{\mathrm{P}}\right)$ versus the reciprocal of absolute temperature, used for obtaining the values of Q.

Fig. 13. Plots of $\ln \mathrm{Z}$ against (a) $\sigma_{\mathrm{P}}$, (b) $\ln \sigma_{\mathrm{P}}$, and (c) $\ln \sinh \left(\alpha \sigma_{\mathrm{P}}\right)$.

Fig. 14. Evaluation the proposed model; (a) red points are the experimental values obtained in this work; (b) triangular and square denote the experimental data taken from Ref. [25] and Ref. [22], respectively, and the solid lines the calculated values using the proposed equation. 


\section{Tables Captions}

Table 1. Chemical composition of IN 718 (wt.\%)

Table 2. Calculated values required to find the average values of $\beta, n^{\prime}$ and $n$ (Eq. (5)) from curves of $\ln \&$ versus $\sigma_{\mathrm{p}}, \ln \sigma_{\mathrm{P}}$ and $\ln [\sinh (\alpha \sigma)]$

Table 3. Calculated values required to find the values of activation energy from plots of $\sigma_{\mathrm{P}}$, $\ln$ $\sigma_{\mathrm{P}}$ and $\ln \sinh \left(\alpha \sigma_{\mathrm{P}}\right)$ versus $1 / \mathrm{T}$

Table 4. Calculated values of $\beta, \mathrm{n}^{\prime}$ and $\mathrm{n}$ from $\ln \mathrm{Z}$ against $\sigma_{\mathrm{P}}, \ln \sigma_{\mathrm{P}}$, or $\ln \sinh \left(\alpha \sigma_{\mathrm{P}}\right)$ curves

Table 1. Chemical composition of IN 718 (wt.\%)

\begin{tabular}{|cccccccccccc|}
\hline $\mathbf{N i}$ & $\mathbf{C r}$ & $\mathbf{F e}$ & $\mathbf{N b}+\mathbf{T a}$ & $\mathbf{M o}$ & $\mathbf{T i}$ & Al & Co & Sl & Mn & Cu & C \\
\hline 54.00 & 18.21 & 17.29 & 5.35 & 2.98 & 0.91 & 0.66 & 0.24 & 0.08 & 0.07 & 0.07 & 0.03 \\
\hline
\end{tabular}

Table 2. Calculated values required to find the average values of $\beta, n$ and $n$ (Eq. (5)) from curves of $\ln \dot{\varepsilon}$ versus $\sigma_{p}$, $\ln \sigma_{P}$ and $\ln [\sinh (\alpha \sigma)]$

\begin{tabular}{|c|cc|cc|cc|}
\hline $\mathbf{T}\left({ }^{\circ} \mathrm{C}\right)$ & \multicolumn{2}{|c|}{ Exponential law } & \multicolumn{2}{c|}{ Power law } & \multicolumn{2}{c|}{ Hyperbolic sine law } \\
& $\boldsymbol{\beta}$ & Adjusted $\mathbf{R}^{2}$ of $\boldsymbol{\beta}$ & $\mathrm{n}^{\prime}$ & Adjusted $\mathbf{R}^{2}$ of $\mathrm{n}^{\prime}$ & $\mathrm{n}$ & Adjusted $\mathbf{R}^{2}$ of $\mathbf{n}$ \\
\hline $\mathbf{9 5 0}$ & 0.020 & 0.9355 & 4.838 & 0.9948 & 2.987 & 0.9644 \\
$\mathbf{1 0 0 0}$ & 0.027 & 0.9838 & 5.501 & 0.9914 & 3.768 & 0.9990 \\
$\mathbf{1 0 5 0}$ & 0.025 & 0.9463 & 4.931 & 0.9926 & 3.389 & 0.9908 \\
$\mathbf{1 1 0 0}$ & 0.031 & 0.9257 & 4.846 & 0.9988 & 3.704 & 0.9905 \\
Average & $\mathbf{0 . 0 2 6}$ & $\mathbf{0 . 9 4 7 8}$ & $\mathbf{5 . 0 2 9}$ & $\mathbf{0 . 9 9 4 4}$ & $\mathbf{3 . 4 6 2}$ & $\mathbf{0 . 9 8 6 2}$ \\
\hline
\end{tabular}


Table 3. Calculated values required to find the values of activation energy from plots of $\sigma_{P}$, $\ln \sigma_{P}$ and $\ln \sinh \left(\alpha \sigma_{P}\right)$ versus $1 / T$

\begin{tabular}{|c|c|c|c|c|c|c|c|c|c|}
\hline \multirow[b]{2}{*}{$\begin{array}{c}\text { Strain } \\
\text { Rate } \\
\left(\mathrm{s}^{-1}\right)\end{array}$} & \multicolumn{3}{|c|}{ Exponential law } & \multicolumn{3}{|c|}{ Power law } & \multicolumn{3}{|c|}{ Hyperbolic sine law } \\
\hline & $\begin{array}{l}\text { Slope of } \\
\sigma_{P}-\frac{1}{T}\end{array}$ & $\begin{array}{c}\text { Adjuste } \\
\text { d } \mathbf{R}^{2} \text { of } \\
\text { slope }\end{array}$ & $\begin{array}{c}\mathbf{Q} \\
(\mathrm{kJJ} / \mathrm{mol})\end{array}$ & $\begin{array}{l}\text { Slope of } \\
\ln \sigma_{P}-\frac{1}{T}\end{array}$ & $\begin{array}{l}\text { Adjusted } \\
\mathbf{R}^{2} \text { of slope }\end{array}$ & $\begin{array}{c}\mathbf{Q} \\
(\mathbf{k J} / \mathbf{m o l})\end{array}$ & $\begin{array}{c}\text { Slope of } \\
\ln \sinh \left(\alpha \sigma_{\mathrm{p}}\right)-\frac{1}{T}\end{array}$ & $\begin{array}{l}\text { Adjusted } \\
\mathbf{R}^{2} \text { of slope }\end{array}$ & $\begin{array}{c}\mathbf{Q} \\
(\mathbf{k J} / \mathbf{m o l} \\
)\end{array}$ \\
\hline 0.001 & 1006467 & 0.9604 & & 11525 & 0.9859 & & 12630 & 0.9855 & \\
\hline 0.01 & 1474900 & 0.9878 & & 10597 & 0.9941 & & 13073 & 0.9980 & \\
\hline 0.1 & 2484764 & 0.9689 & & 10902 & 0.9972 & & 17219 & 0.9864 & \\
\hline 1 & 2190106 & 0.9936 & & 7792 & 0.9999 & & 14117 & 0.9966 & \\
\hline 10 & 3064037 & - & & 8106 & - & & 18793 & - & \\
\hline $\begin{array}{c}\text { Averag } \\
\text { e }\end{array}$ & 2044055 & 0.9777 & 442 & 9784 & 0.9943 & 409 & 15166 & 0.9916 & 437 \\
\hline
\end{tabular}

Table 4. Calculated values of $\beta$, $n$ and $n$ from $\ln Z$ against $\sigma_{P}$, $\ln \sigma_{P}$, or $\ln \sinh \left(\alpha \sigma_{P}\right)$ curves

\begin{tabular}{|c|c|c|c|c|c|}
\hline \multicolumn{2}{|c|}{ Exponential law } & \multicolumn{2}{|c|}{ Power law } & \multicolumn{2}{|c|}{$\begin{array}{l}\text { Hyperbolic sine law } \\
\text { Adjusted } \mathbf{R}^{2} \text { of }\end{array}$} \\
\hline$\beta$ & $\begin{array}{c}\text { Adjusted } \mathbf{R}^{2} \text { of } \\
\text { B }\end{array}$ & $\mathrm{n}^{\prime}$ & Adjusted $\mathbf{R}^{2}$ of $\mathrm{n}^{\prime}$ & n & $\begin{array}{c}\text { Adjusted R } \\
\text { n }\end{array}$ \\
\hline 0.027 & 0.9423 & 4.957 & 0.9935 & 3.562 & 0.9889 \\
\hline
\end{tabular}




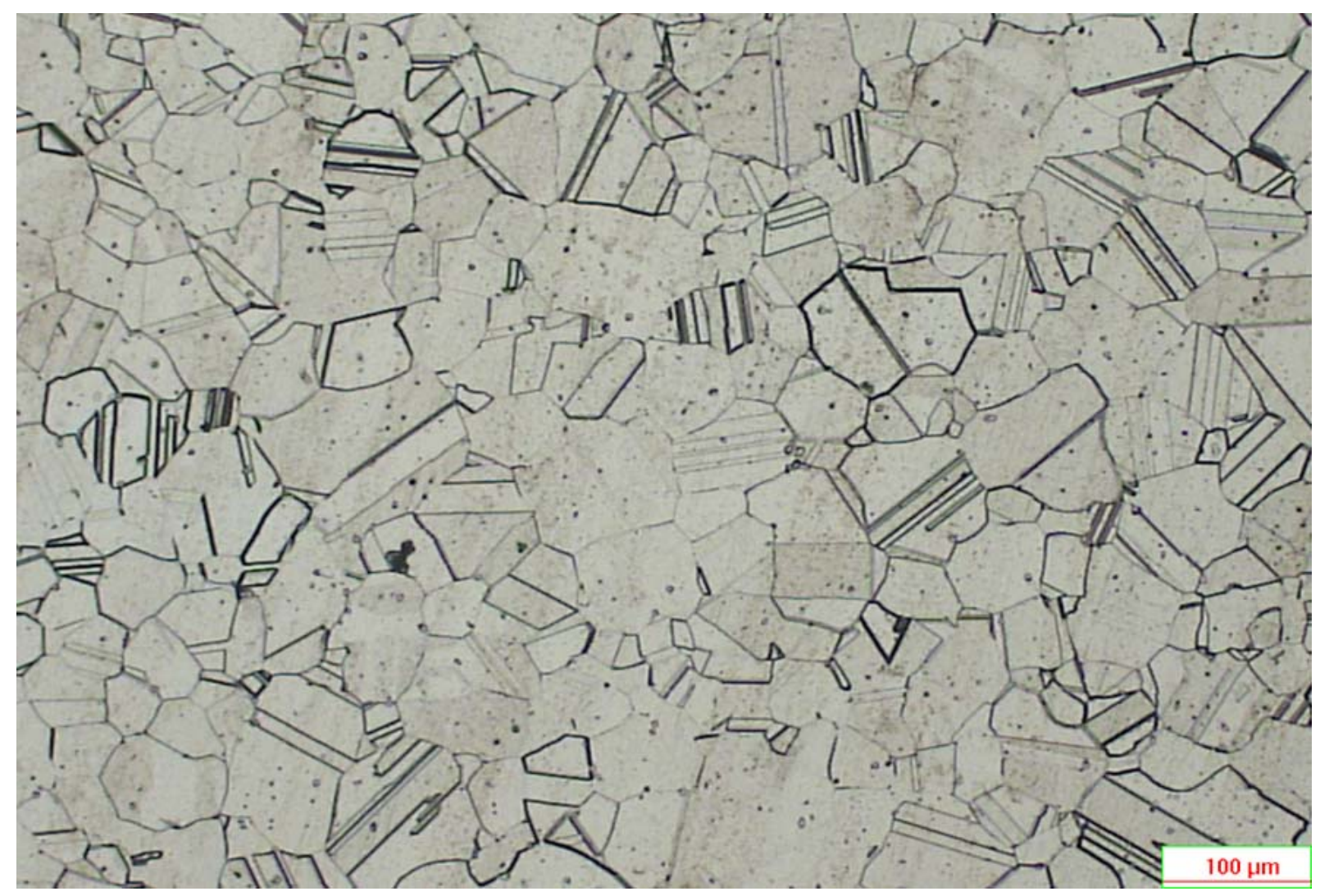

Fig. 1. Optical micrograph of the studied IN718 before hot deformation. 

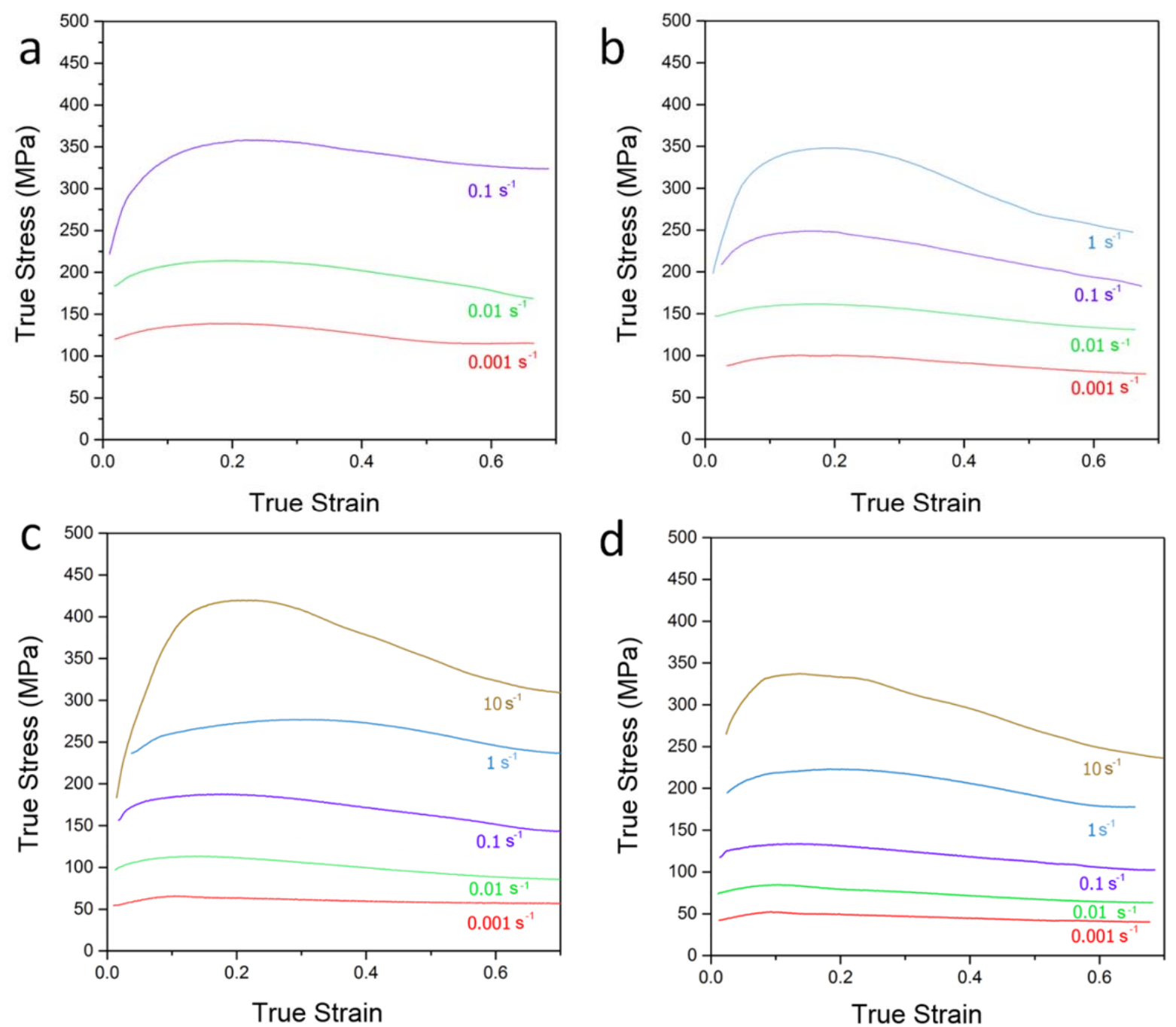

Fig. 2. True stress-true strain curves obtained in hot compression of IN718 at different strain rates and temperatures of (a) 950, (b) 1000 , (c) 1050 and (d) $1100{ }^{\circ} \mathrm{C}$. 
a

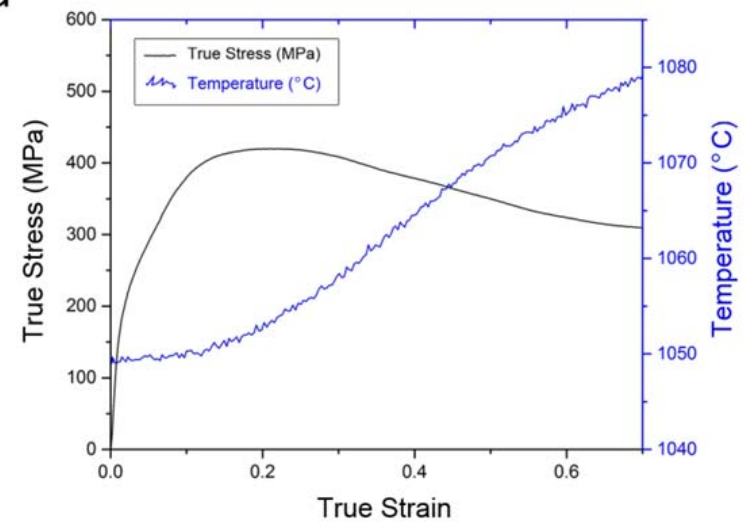

b

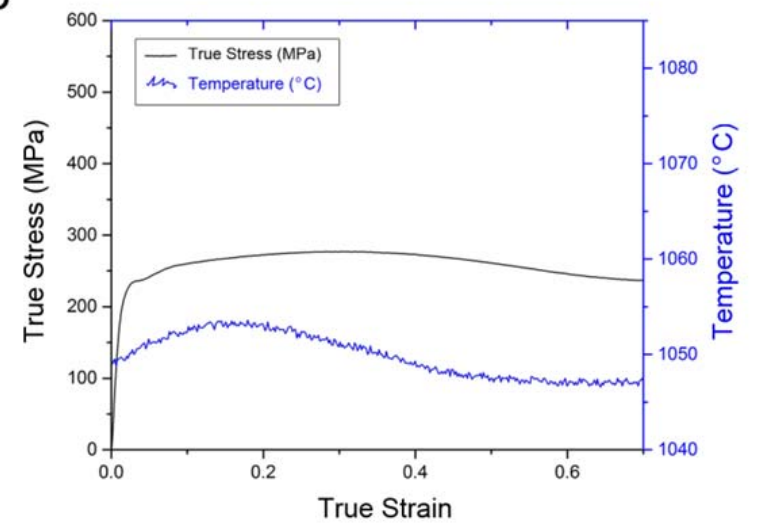

Fig. 3. (a) True stress and temperature versus true strain curves for samples deformed at $1050{ }^{\circ} \mathrm{C}$ and strain rate of (a) 10 and (b) $1 \mathrm{~s}^{-1}$.
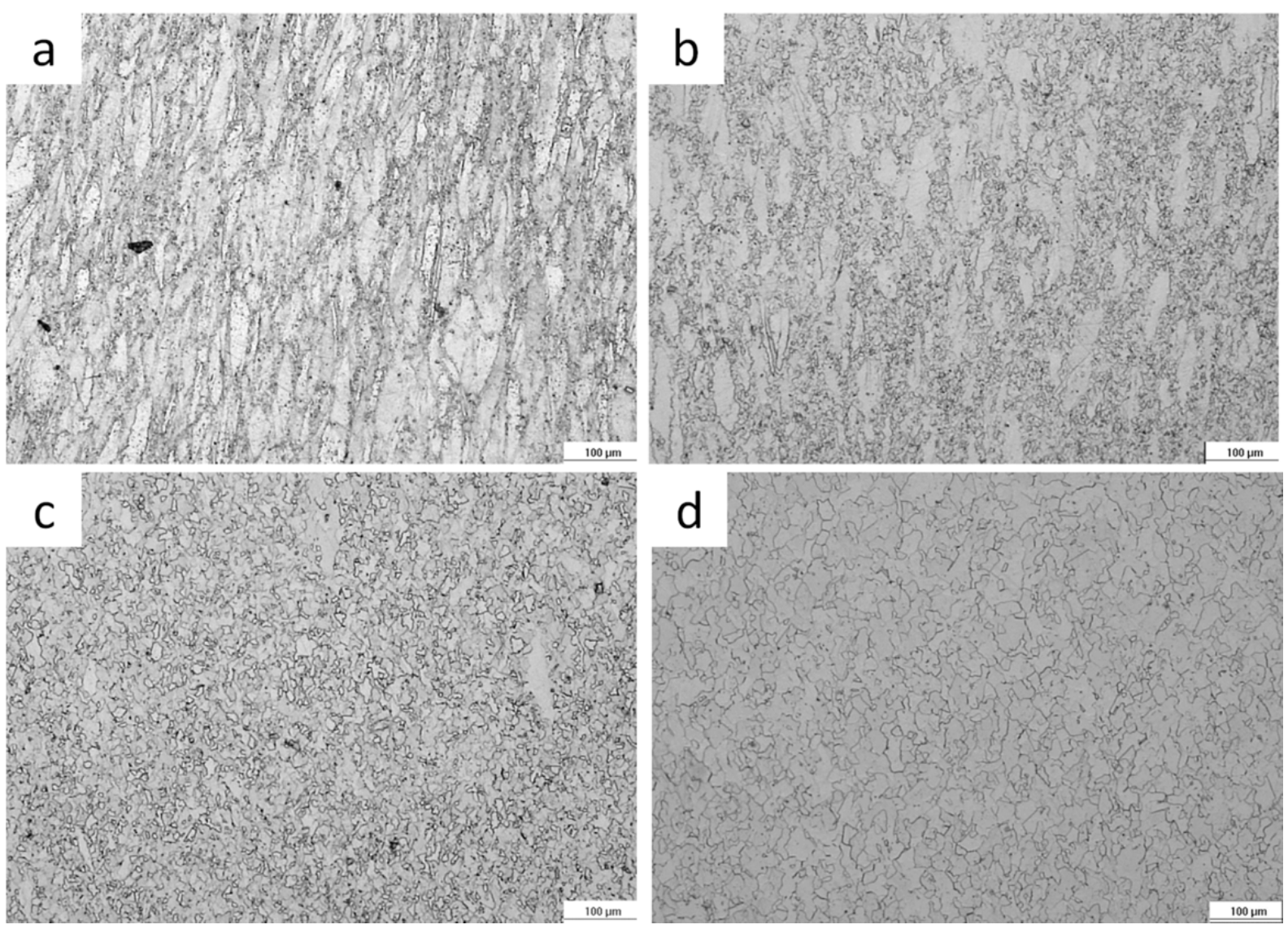
Fig. 4. Microstructure of IN718 alloy deformed at strain rate of $0.01 \mathrm{~s}^{-1}$ and temperature of (a) 950, (b) 1000, (c) 1050 and (d) $1100{ }^{\circ} \mathrm{C}$; showing DRX microstructures.
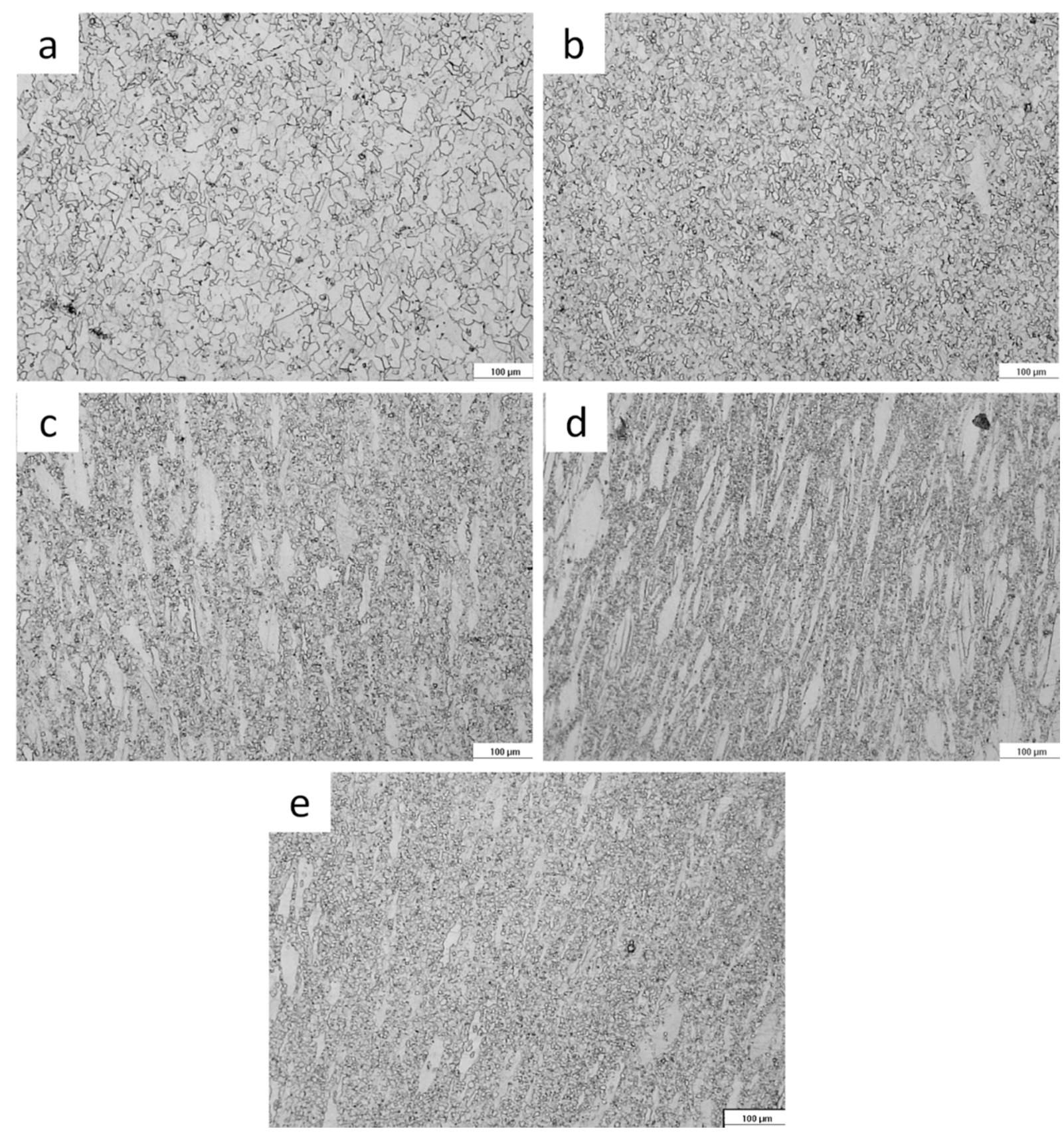

Fig. 5. Microstructure of IN718 alloy deformed at strain rate of (a) 0.001 , (b) 0.01 , (c) 0.1 , (d) 1 and (e) $10 \mathrm{~s}^{-1}$, and $1050{ }^{\circ} \mathrm{C}$; showing DRX microstructures. 

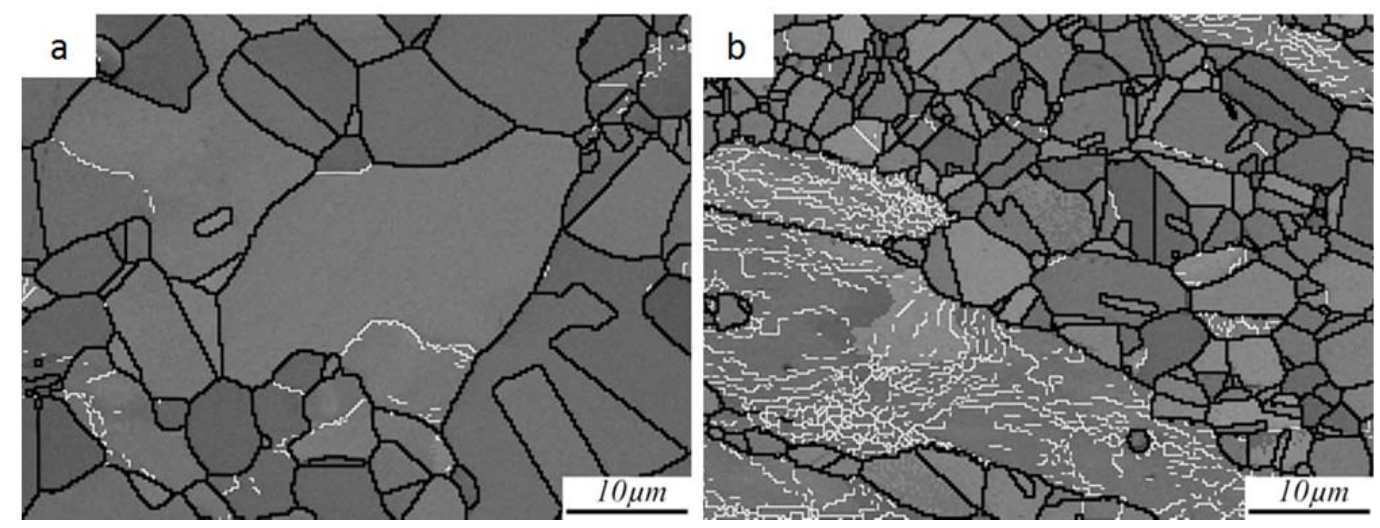

Fig. 6. The OIM band contrast microstructures for samples deformed at $1100^{\circ} \mathrm{C}$ and strain rate of (a) $0.1 \mathrm{~s}^{-1}$ and (b) $10 \mathrm{~s}^{-1}$. The high and low angle boundaries are shown as black and white lines, respectively.
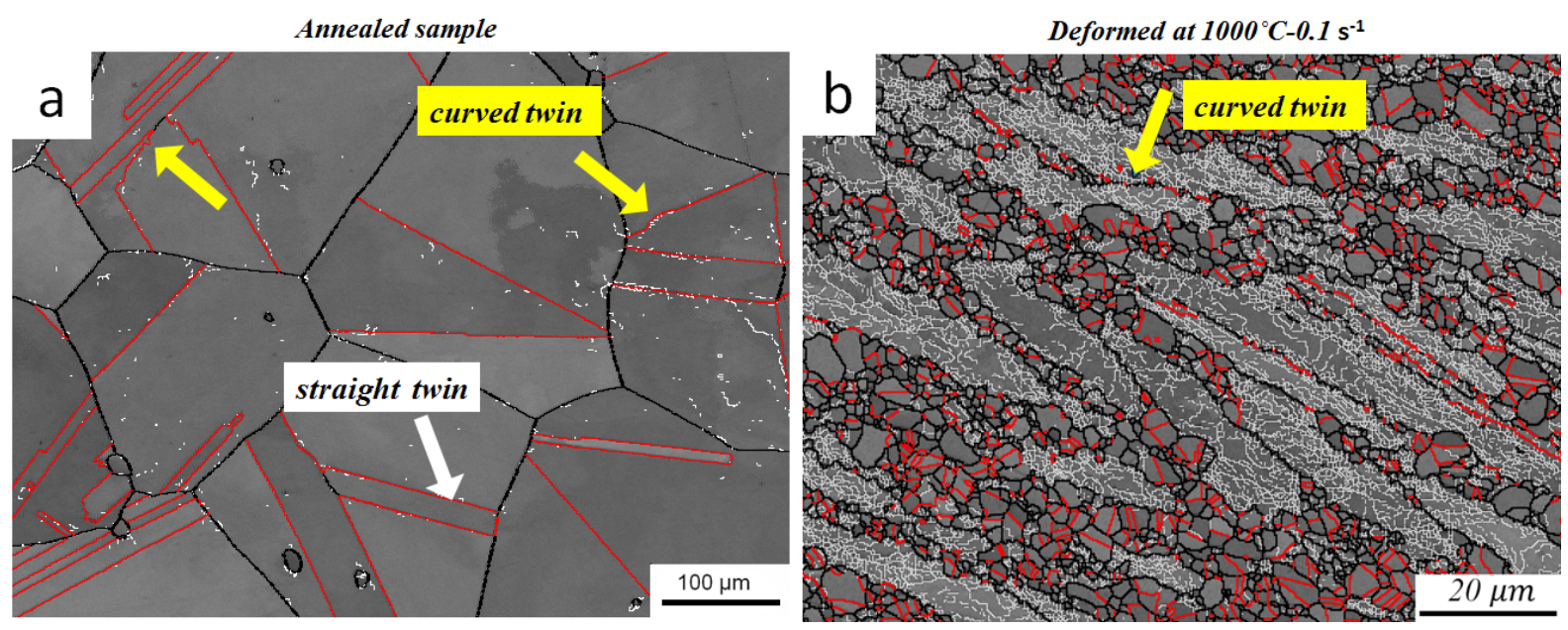

Fig. 7. The OIM band contrast microstructures for (a) annealed sample and (b) sample deformed at $1000^{\circ} \mathrm{C}-0.1 \mathrm{~s}^{-1}$; the high and low angle boundaries are shown as black and white lines, respectively; $\Sigma 3$ twin boundaries are shown as red lines. 

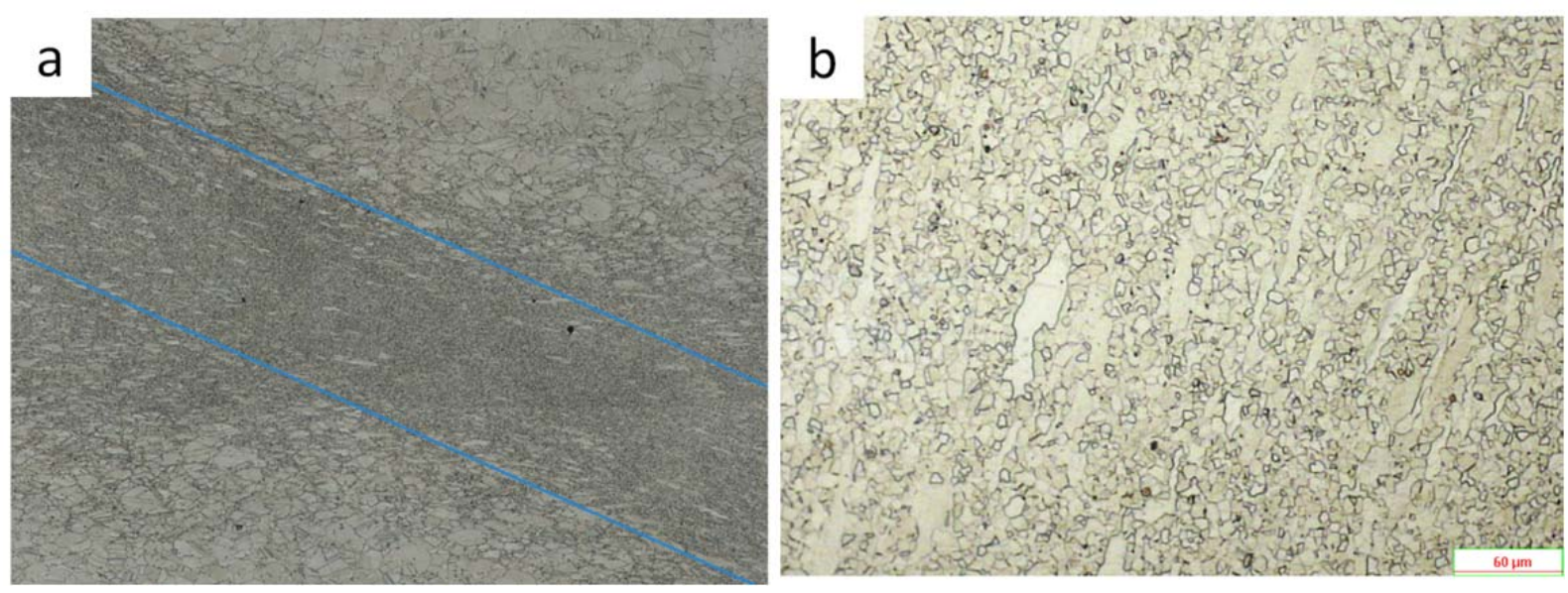

Fig. 8. (a) Macrograph and (b) micrograph of IN 718 alloy deformed at $1050{ }^{\circ} \mathrm{C}-10 \mathrm{~s}^{-1}$.

a

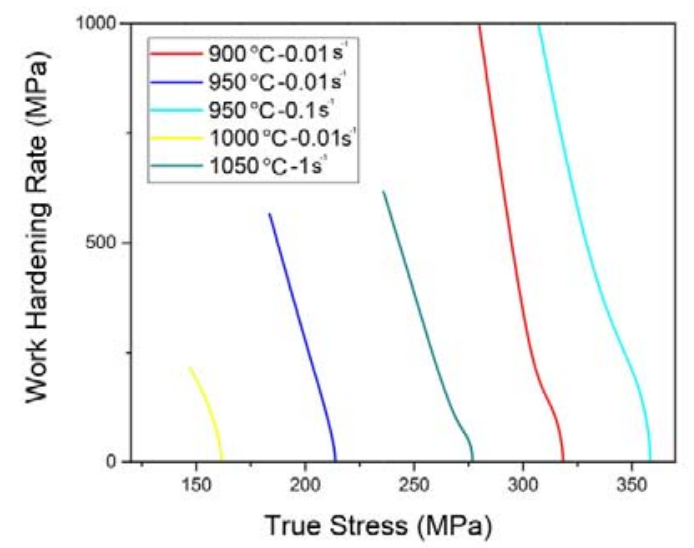

b

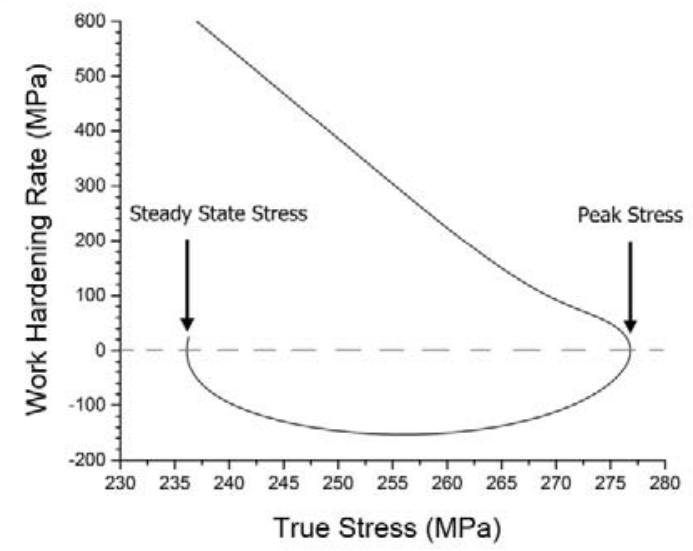

Fig. 9. (a) Some of work hardening rate-true stress curves in various conditions; (b) Method used for determination of peak and steady state stresses. 

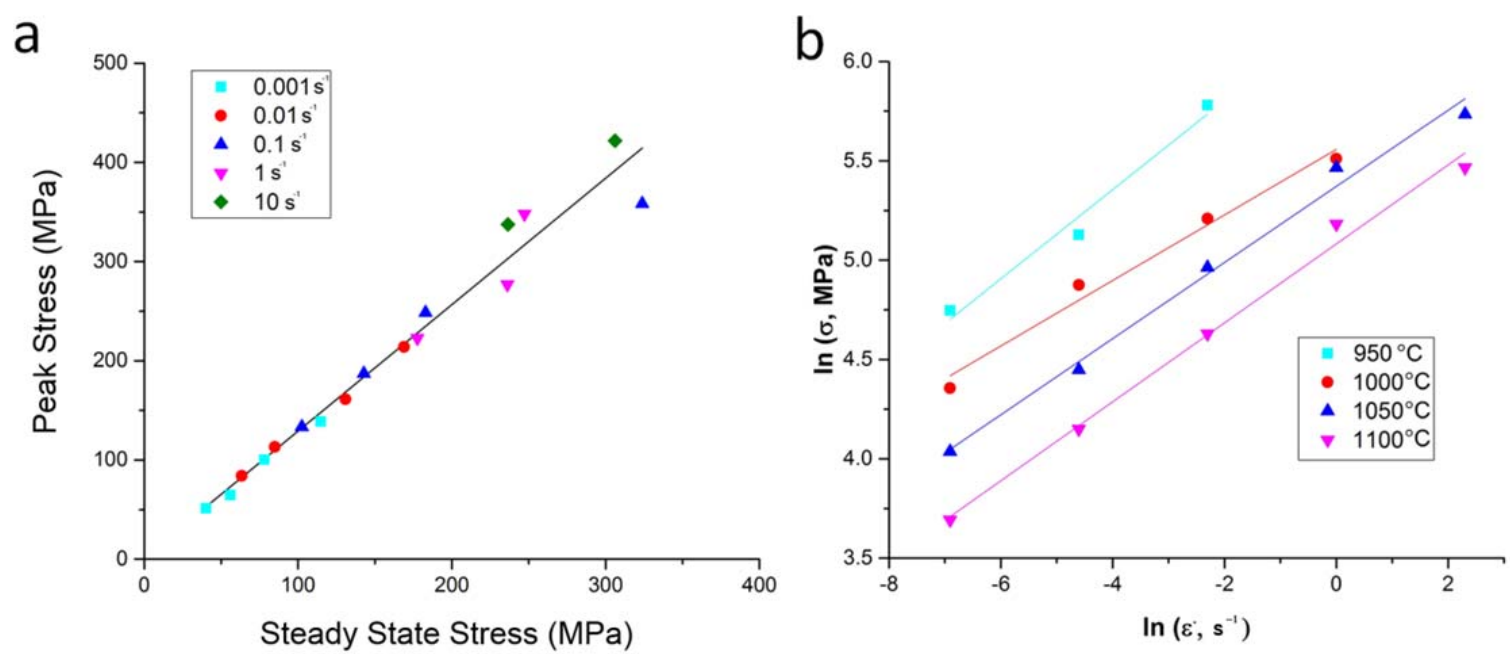

Fig. 10. The linear relationship between (a) the peak stress and steady state stress at various strain rates, and (b) variations of $\ln \sigma$ and $\ln \&$ 

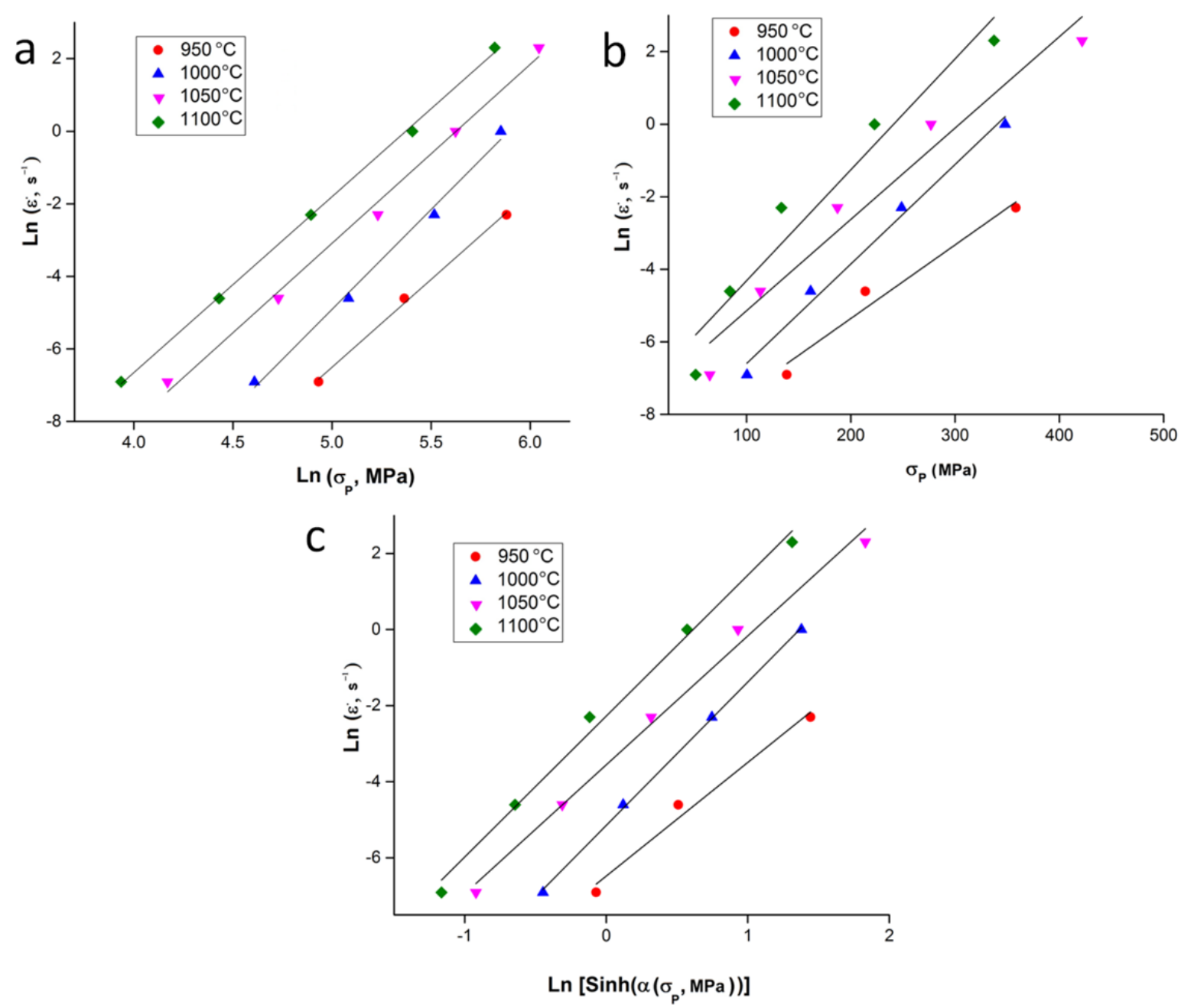

Fig. 11. Plots used for calculation of (a) $n^{\prime}$, (b) $\beta$ and (c) $n$ values. 

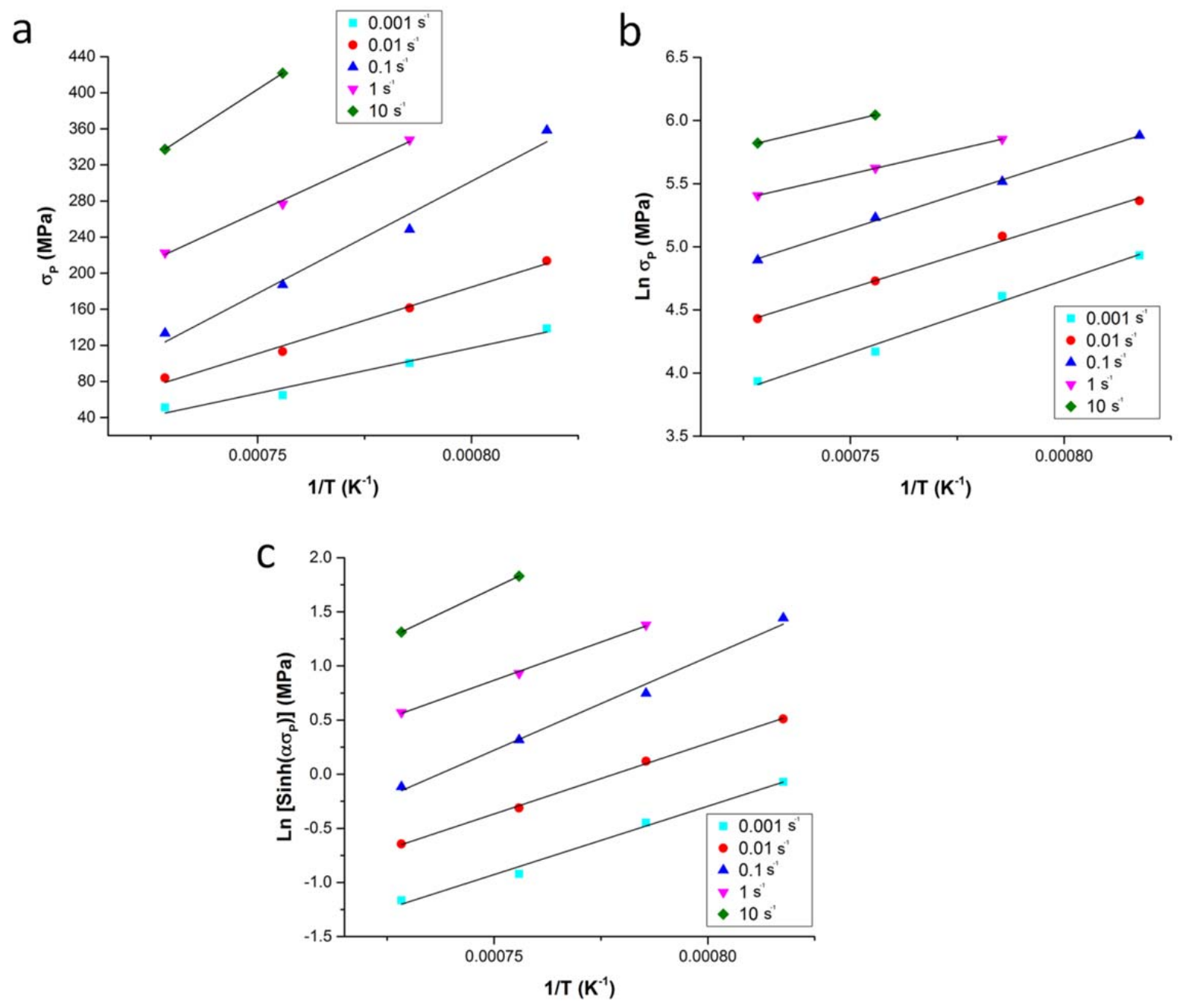

Fig. 12. Plots of (a) $\sigma_{\mathrm{P}}$, (b) $\ln \sigma_{\mathrm{P}}$, and (c) $\ln \sinh \left(\alpha \sigma_{\mathrm{P}}\right)$ versus the reciprocal of absolute temperature, used for obtaining the values of Q. 

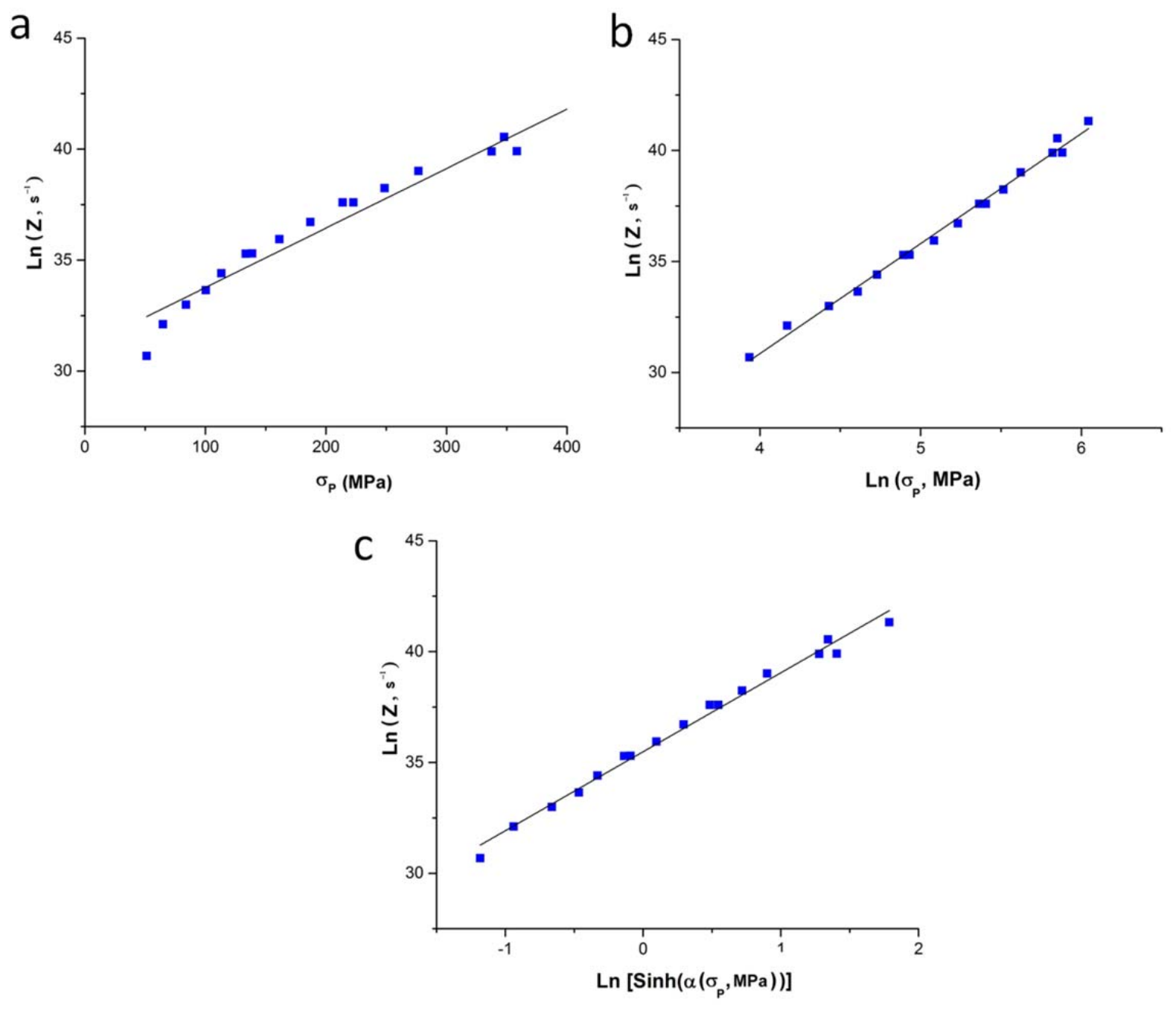

Fig. 13. Plots of $\ln Z$ against (a) $\sigma_{\mathrm{P}}$, (b) $\ln \sigma_{\mathrm{P}}$, and (c) $\ln \sinh \left(\alpha \sigma_{\mathrm{P}}\right)$. 
a

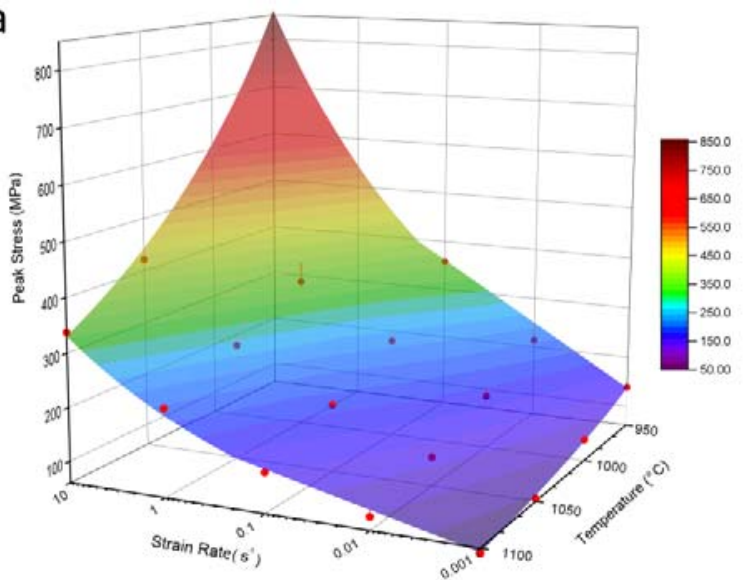

b

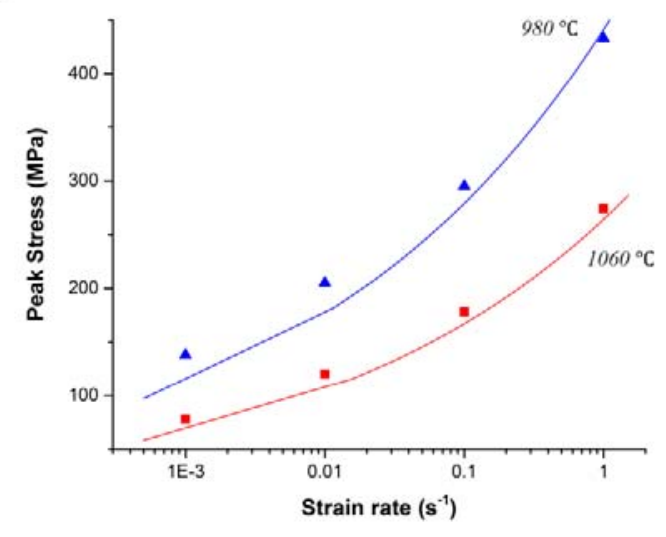

Fig. 14. Evaluation the proposed model; (a) red points are the experimental values obtained in this work; (b) triangular and square denote the experimental data taken from Ref. [25] and Ref. [22], respectively, and the solid lines the calculated values using the proposed equation. 